\title{
World Kidney Day 2011: Protect Your Kidneys, Save Your Heart
}

\author{
William G. Couser ${ }^{a}$ Miguel C. Riella ${ }^{b}$ \\ ${ }^{a}$ Global Outreach Programs, International Society of Nephrology, and University of Washington School of \\ Medicine, Seattle, Wash., USA; ${ }^{b}$ International Federation of Kidney Foundations KDIGO, International Society of \\ Nephrology, and Catholic University of Parana, Curitiba, Brazil
}

\section{Introduction to World Kidney Day 2011}

March 10, 2011 will mark the celebration of the 6th World Kidney Day (WKD), an annual event jointly sponsored by the International Society of Nephrology and the International Federation of Kidney Foundations. Since its inception in 2006, WKD has grown dramatically to become the most widely celebrated event associated with kidney disease in the world and the most successful effort to raise awareness among both the general public and government health officials about the dangers of kidney disease, especially chronic kidney disease (CKD).

In 2011, WKD will call attention to the large, and often unappreciated, role played by kidney dysfunction in increasing premature cardiovascular disease, the most common cause of morbidity and mortality worldwide [1].

Can a focus on early detection and prevention of kidney disease really improve long-term cardiovascular health? In this editorial, we hope to convey the message that increased attention to the kidneys can indeed improve long-term health outcomes by reducing both kidney and cardiovascular disease and should therefore be a central component of any global health strategy intended to reduce the enormous and growing burden of chronic NCDs.

\section{KARGER}

(C) 2011 S. Karger AG, Basel

Fax +4161306 1234

E-Mail karger@karger.ch

www.karger.com
Accessible online at:

www.karger.com/nec

\section{Cardiovascular Disease and the Kidney}

CVD is the most common of the chronic NCDs that impact global mortality. About $30 \%$ of all deaths worldwide and $10 \%$ of all healthy life lost to disease are accounted for by CVD alone [1]. Although there has been some decline in mortality from CVD in developed countries, no such decline has been reported in developing countries, ethic and socially disadvantaged minority populations or in people with accompanying $\operatorname{CKD}[2,3]$.

The presence of CKD significantly increases the risk of a CV event in both diabetes and hypertension $[4,5]$. However, less well appreciated is that CKD alone is a strong risk factor for CVD, independent of diabetes, hypertension or any other conventional CVD risk factor [6, 7]. This is especially true when an increase in proteinuria, a major target of any CKD screening program, is present [6-9].

The authors would like to acknowledge William G. Couser (ISN), Miguel C. Riella (IFKF), co-chairmen, Georgi Abraham, Paul Beerkens, John Feehally, Guillermo Garcia Garcia, Jan Lantik, Dan Larsen, Philip $\mathrm{Li}$, Mark Murphy and Bernardo Rodriguez-Iturbe. For the Joint International Society of Nephrology (WGC) and International Federation of Kidney Foundations (MCR) World Kidney Day 2011 Steering Committee.
Sara Martin

Campaign Manager World Kidney Day

Global Operations Center

Rue du Luxembourg 22-24, BE-1000 Brussels (Belgium)

E-Mail smartin@isn-online.org 
The 20-30-fold increase in CVD in patients with ESRD has long been recognized, but the increased risk for CVD associated with lesser degrees of renal functional impairment was definitively demonstrated only in 2004. Go et al. reported an independent and graded association between GFR and risk of death, CV events and hospitalizations was reported in a community-based study of over 1,000 individuals [6].

Is this dramatic increase in CVD risk associated with CKD really due to CKD or does it just reflect the coexistent diabetes or hypertension that are present in a majority of these patients? The independent effect of CKD alone has now been well documented in many studies [7]. The risk of cardiac death is increased $46 \%$ in people with a GFR between 30 and $60 \mathrm{ml} / \mathrm{min}$ (Stage III CKD) independent of traditional CV risk factors including diabetes and hypertension [10]. The increased risk for CV events and mortality in people over 55 with CKD alone is equivalent, or even higher, to that seen in patients with diabetes or previous myocardial infarcts [11]. Both general $[6,12]$ and high-risk populations $[13,14]$ exhibit an increased risk of CVD with CKD. This increased risk for CVD is not confined to the elderly - in volunteers with an average age of 45 , the risk for myocardial infarct, stroke and all cause mortality was doubled in those with CKD [14].

\section{Proteinuria and CV Risk}

In considering the value of recommending screening for CKD along with conventional CVD risk factors in selected individuals data showing that the risk of CVD is better correlated with proteinuria (albuminuria), than with GFR alone is particularly relevant because proteinuria is virtually always a marker of kidney disease and is not a conventional CVD risk factor $[6,8,9,15]$.

With regard to proteinuria as a predictor of later CVD, The PREVEND study showed a direct linear relationship between albuminuria and risk of $\mathrm{CV}$ death in the general population even at levels of albumin excretion generally considered within the 'normal' range (15-29 mg/day) and was increased more than 6 fold when albumin excretion exceeded $300 \mathrm{mg} /$ day [8].

Recent data from the US NHANES database as well as from Japan also document an independent effect of albuminuria on risk of both CVD and all cause mortality at all levels of GFR $[15,16]$. In patients with congestive heart failure but without diabetes, hypertension or reduced GFR, increased urinary albumin predicts both CV and all cause mortality [17]. Similar results are obtained studying patients with coronary disease or previous myocardial infarcts in whom proteinuria conferred a greater risk of mortality than reduced GFR, although both adversely impacted outcomes [18].

Of interest, not only the likelihood but also the time to development of a CV event is accelerated significantly by the presence of proteinuria at all levels of GFR [19]. In non-diabetic subjects with normal serum creatinine levels undergoing percutaneous coronary interventions, about $78 \%$ have demonstrable CKD when screened more stringently for renal function (eGFR, urine protein) [20]. Not only is the presence of CKD a likely factor in accelerating development of coronary disease in these patients but it has also been associated with an increase in other risks including hemorrhagic complications, contrast nephropathy, re-stenosis, and death [10]. Thus, multiple studies now confirm that proteinuria is a graded risk factor for CVD independent of GFR, hypertension and diabetes and that this risk extends down into ranges of albumin excretion generally considered 'normal' [21, 22]. Moreover, this increased CV risk has been well demonstrated in several studies where only dipsticks were used to screen for increased protein excretion $[6,18,23]$.

Although there has been concern that CKD diagnosed by reduced GFR alone identifies predominately older adults at increased risk because of age alone [24], the connection between proteinuria as an independent risk factor for CV mortality has been confirmed by meta-analysis of 22 separate, general population, cohort studies and in both older $(>65)$ and younger people of several nationalities and racial groups [23].

\section{Can Treatment of CKD Reduce CVD?}

Finally, and most importantly from a clinical perspective, there is provocative data to suggest that renal-targeted interventions designed to reduce proteinuria and slow progression of CKD can reduce CVD risk as well. ACEI and/or ARBs are of documented benefit in slowing progression of established diabetic and non-diabetic CKD [25-29]. Of interest related to slowing progression, the incidence of CVD in CKD is significantly higher with more rapid loss of GFR independent of other risk factors, suggesting that interventions that slow progression may also reduce CVD [19]. A 44\% reduction in CV mortality over 4 years has been reported in patients screened from a general population with no risk factors except increased albumin in the urine and treated with renal-targeted ACEI therapy [30]. This effect was seen primarily in peo- 
ple with albumin excretion rates of $>50 \mathrm{mg} /$ day in a pilot study, and the intervention was shown to be cost effective in that population [31]. CV endpoints were significantly reduced in direct proportion to the reduction of albuminuria with ACEI therapy, and albuminuria proved to be the only predictor of CV outcome [32]. Other studies have also demonstrated that changes in proteinuria (in diabetics) better predict outcomes than changes in BP achieved with ACEI therapy [33]. The potential benefit of renaltargeted therapies has recently been highlighted by observations that higher doses of renin-angiotensin system (RAS) blockers than required for BP control alone can further reduce proteinuria independent of effects on BP or GFR, and that addition of salt restriction or diuretics, both very inexpensive interventions, can further enhance the proteinuria-reducing effect of RAS blockade [34, 35]. Data are not yet available to establish that screening for $\mathrm{CKD}$ and subsequent interventions will reduce $\mathrm{CV}$ mortality and be cost-effective in younger people $(<55)[36]$. However, it is now known that albuminuria is a better predictor of renal and cardiovascular events than blood pressure alone, that reducing proteinuria is more renal and cardio protective than lowering blood pressure alone and that identification of CKD can improve CV outcomes.

\section{Conclusion}

As celebrations of the sixth World Kidney Day approach on March 10, 2011, it is worth noting that prior to the past decade, kidney disease was seen by most government and public health authorities as largely confined to patients with ESRD, thankfully a rare condition because the enormous cost of renal replacement therapy disproportionately consumes scarce health care resources and is well beyond the means of countries inhabited by over $80 \%$ of the worlds population [37,38]. Much has changed. We now appreciate that kidney disease is not rare - some $10 \%$ of the population has evidence of renal dysfunction. And we know these individuals are not of concern just because a few will progress to ESRD, but more because they carry a greatly enhanced risk of premature death from CVD, the single largest and most expensive health care threat we confront at a global level [1]. Just as progress is being made in treating most of the traditional CV risk factors, CKD has emerged as yet another one that causes substantial vascular toxicity independently. Fortunately, there is good news as well. Biomarkers of CKD (proteinuria, eGFR) are easy and relatively inexpensive to detect, and one of these, proteinuria, emerges early in the evolution of generalized vascular disease. Thus kidneytargeted detection and prevention programs seem to offer a valuable opportunity to institute early preventive measures that go beyond traditional cardio-protective approaches. There is now compelling evidence that including selective screening for CKD in global health programs designed primarily to reduce CVD will significantly improve the outcomes of not only renal disease, but especially the NCDs like diabetes and CVD that dominate future health care strategies. Roadmaps for accomplishing this have already been presented for both developed $[39,40]$ and emerging $[1,41]$ countries. However, effective implementation of such strategies will only come when both the general public and the renal community work together to convince health authorities it is in the public interest to do this. It is our sincere hope that worldwide celebration of World Kidney Day 2011 will provide an opportunity to reinforce the message that kidney disease is indeed common, harmful and treatable and that protecting your kidneys is an important health strategy that may save your heart.

\section{References}

1 World Health Organization. Preventing Chronic Diseases: A Vital Investment: WHO Global Report 2005. 2008-2013 action plan for the global strategy for the prevention and control of noncommunicable diseases: prevent and control cardiovascular diseases, cancers, chronic respiratory diseases and diabetes.

2 Anderson GF, Chu E: Expanding priorities confronting chronic disease in countries with low income. N Engl J Med 2007;356:209-211.

3 Narayan KM, Ali MK, Koplan JP: Global noncommunicable diseases - where worlds meet. N Engl J Med 2010;363:1196-1198.
4 Ritz E, Bakris G; World Kidney Day Organising Committee: World Kidney Day: hypertension and chronic kidney disease. Lancet 2009;373:1157-1158.

5 Atkins RC, Zimmet P; ISN-IFKF World Kidney Day Steering Committee: Diabetic kidney disease: act now or pay later. Nat Rev Nephrol 2010;6:134-136.

6 Go AS, Chertow GM, Fan D, McCulloch CE, Hsu CY: Chronic kidney disease and the risks of death, cardiovascular events, and hospitalization. N Engl J Med 2004;351: 1296-305.
7 Tonelli M, Wiebe N, Culleton B, House A, Rabbat C, Fok M, McAlister F, Garg AX: Chronic kidney disease and mortality risk: a systematic review. J Am Soc Nephrol 2006; 17:2034-2047.

8 Hillege HL, Fidler V, Diercks GFH, van Gilst WH, de Zeeuw D, van Veldhuisen DJ, Gans ROB, Janssen WMT, Grobbee DE, de Jong PE; for the PREVEND study group: Urinary albumin excretion predicts cardiovascular and noncardiovascular mortality in general population. Circulation 2002;106:17771782 .

World Kidney Day 2011 
9 Klausen K, Borch-Johnsen K, Feldt-Rasmussen B, Jensen G, Clausen P, Scharling $\mathrm{H}$, Appleyard M, Jensen JS: Very low levels of microalbuminuria are associated with increased risk of coronary heart disease and death independently of renal function, hypertension, and diabetes. Circ 2004;110: 32-35.

10 van Domburg RT, Hoeks SE, Welten GMJM, Chonchol M, Elhendy A, Poldermans D: Renal insufficiency and mortality in patients with known or suspected coronary artery disease. J Am Soc Neph 2008;19:158-163.

11 Rashidi A, Sehgal AR, Rahman M, O’Connor AS: The case for chronic kidney disease, diabetes mellitus, and myocardial infarction being equivalent risk factors for cardiovascular mortality in patients older than 65 years. Am J Cardiol 2008;102:1668-1667.

12 McCullough PA, Li S, Jurkovitz CT, Stevens LA, Wang C, Collins AJ, Chen SC, Norris KC, McFarlane SI, Johnson B, Shlipak MG, Obialo CI, Brown WW, Vassalotti JA, Whaley-Connell AT; Kidney Early Evaluation Program Investigators: CKD and Cardiovascular Disease in Screened High-Risk Volunteer and General Populations: The Kidney Early Evaluation Program (KEEP) and National Health and Nutrition Examination Survey (NHANES) 1999-2004. Am J Kidney Ds 2008;51:S38-S45.

13 McCullough PA, Jurkovitz CT, Pergola PE, McGill JB, Brown WW, Collins AJ, Chen SC, Li S, Singh A, Norris KC, Klag MJ, Bakris GL; for the KEEP Investigators: Independent components of chronic kidney disease as a cardiovascular risk state: results from the Kidney Early Evaluation Program (KEEP). Arch Intern Med 2007;167:1122-1129.

14 McCullough PA, Li S, Jurkovitz CT, Stevens L, Collins AJ, Chen SC, Norris KC, McFarlane S, Johnson B, Shlipak MG, Obialo CI, Brown WW, Vassalotti J, Whaley-Connell AT, Brenner RM, Bakris GL; KEEP Investigators: Chronic kidney disease: prevalence of premature cardiovascular disease and relationship to short-term mortality. Am Heart J 2008; 156:277-283.

15 Astor BC, Hallan SI, Miller ER 3rd, Yeung E, Coresh J: Glomerular filtration rate, albuminuria, and risk of cardiovascular and allcause mortality in the US population. Am J Epidemiol 2008;167:1226-1233.

16 Irie F, Iso H, Sairenchi T, Fukasawa N, Yamagishi K, Ikehara S, Kanashiki M, Saito Y, Ota H, Nose T: The relationships of proteinuria, serum creatinine, glomerular filtration rate with cardiovascular disease mortality in Japanese general population. Kidney Int 2006;69:1264-1271.

17 Granger CB, Swedberg K, Pfeffer MA, Yusuf S, McMurray JJ; CHARM Investigators: Individuals at increased renal risk. J Am Soc Nephrol 2009;20:852-862.

18 Tonelli M, Jose P, Curhan G, Sacks F, Braunwald E, Pfeffer M; Cholesterol and Recurrent Events (CARE) Trial Investigators: Proteinuria, impaired kidney function, and adverse outcomes in people with coronary disease: analysis of a previously conducted randomised trial. BMJ 2006;332:1426.

19 Matsushita K, Selvin E, Bash LD, Franceschini N, Astor BC, Coresh J: Change in estimated GFR associates with coronary heart disease and mortality. J Am Soc Nephrol 2009;20:2617-2624.

20 Malyszko J, Bachorzewska-Gajewska H, Malyszko JS, Dobrzycki SMalyszko J, Bachorzewska-Gajewska H, Malyszko JS, Dobrzycki S: Prevalence of chronic kidney disease in elderly patients with normal serum creatinine levels undergoing percutaneous coronary interventions. Gerontol 2010;56: 51-54.

21 Hemmelgarn BR, Manns BJ, Lloyd A, James MT, Klarenbach S, Quinn RR, Wiebe N, Tonelli M; Alberta Kidney Disease Network: Relation between kidney function, proteinuria, and adverse outcomes. JAMA 2010;303: 423-429.

22 Gansevoort RT, de Jong PE: The case for using albuminuria in staging chronic kidney disease. J Amer Soc Nephrol 2009;20:465-468.

23 Chronic Kidney Disease Prognosis Consortium: Association of estimated glomerular filtration rate and albuminuria with allcause and cardiovascular mortality in general population cohorts: a collaborative meta-analysis. Lancet 2010;375:2073-2081.

24 Abdelhafiz AH, Brown SHM, Bello A, El Nahas M: Chronic kidney disease in older people: physiology, pathology or both? Nephron Clin Pract 2010;116:c19-c24.

25 Brenner BM, Cooper ME, de Zeeuw D, Keane WF, Mitch WE, Parving HH, Remuzzi G, Snapinn SM, Zhang Z, Shahinfar S: Effects of losartan on renal and cardiovascular outcomes in patients with type 2 diabetes and nephropathy. N Engl J Med 2001;345:861-869.

26 Ruggenenti P, Perna A, Gherardi G, Garini G, Zoccali C, Salvadori M, Scolari F, Schena FP, Remuzzi G: Renoprotective properties of ACE-inhibition in non-diabetic nephropathies with non-nephrotic proteinuria. Lancet 1999;354:359-364.

27 Ruggenenti P, Perna A, Gherardi G, Gaspari F, Benini R, Remuzzi G: Renal function and requirement for dialysis in chronic nephropathy patients on long-term ramipril: REIN follow-up trial. Gruppo Italiano di Studi Epidemiologici in Nefrologia (GISEN). Ramipril Efficacy in Nephropathy. Lancet 1998;352:1252-1256.

28 The GISEN Group (Gruppo Italiano di Studi Epidemiologici in Nefrologia): Randomised placebo-controlled trial of effect of ramipril on decline in glomerular filtration rate and risk of terminal renal failure in proteinuric, non-diabetic nephropathy. Lancet 1997;349: 1857-1863.

29 The ESCAPE trial group: Strict blood pressure control and progression of renal failure in children. New Engl J Med 2009;361:1639_ 1650 .

30 Asselbergs FW, Diercks GF, Hillege HL, van Boven AJ, Janssen WM, Voors AA, de Zeeuw D, de Jong PE, van Veldhuisen DJ, van Gilst WH; Prevention of Renal and Vascular End- stage Disease Intervention Trial (PREVEND IT) Investigators: Effects of fosinopril and pravastatin on cardiovascular events in subjects with microalbuminuria. Circulation 2004;110:2809-2816.

31 Atthobari J, Asselbergs FW, Boersma C, de Vries R, Hillege HL, van Gilst WH, Gansevoort RT, de Jong PE, de Jong-van den Berg LT, Postma MJ; PREVEND IT Study Group: Cost-effectiveness of screening for albuminuria with subsequent fosinopril treatment to prevent cardiovascular events: a pharmacoeconomic analysis linked to the prevention of renal and vascular endstage disease (PREVEND) study and the prevention of renal and vascular endstage disease intervention trial (PREVEND IT). Clin Ther 2006;28: 432-444.

32 de Zeeuw D, Remuzzi G, Parving HH, Keane WF, Zhang Z, Shahinfar S, Snapinn S, Brenner BM: Albuminuria: a therapeutic target for cardiovascular protection in type 2 diabetic nephropathy. Circulation 2004; 110:921-927.

33 Eijkelkamp WB, Zhang Z, Remuzzi G, et al: Albuminuria is a target for renoprotective therapy independent from blood pressure in type II diabetic patients with nephropathy. Post hoc analysis from the Reduction in End Points in NIDDM with the Angiotensin II Antagonist Losartan (RENAAL) trial. J Am Soc Nephrol 2007;18:1540-1546.

34 Muirhead N, Rene de Cotret P, Chiu A, Pichette V, Tobe S; SMART (Supra Maximal Atacand Renal Trial) Investigators: Supramaximal dose of candesartan in proteinuric renal disease. J Am Soc Nephrol 2009;20: 893-900.

35 Vogt L, Waanders F, Boomsma F, de Zeeuw D, Navis G: Effects of dietary sodium and hydrochlorothiazide on the antiproteinuric efficacy of losartan. J Am Soc Nephrol 2008;19: 999-1007.

36 Fried L: Are we ready to screen the general population for microalbuminuria? J Am Soc Nephrol 2009;20:686-688.

37 El Nahas M: The global challenge of chronic kidney disease. (Nephrology Forum) Kidney Int 2005;68:2918-2929.

38 Barsoum RS: Chronic Kidney disease in the developing world. New Engl J Med 2006;354: 997-999.

39 Levey AS, Schoolwerth AC, Burrows NR, Williams DE, Stith KR, McClellan W; Centers for Disease Control and Prevention Expert Panel: Comprehensive public health strategies for preventing the development, progression, and complications of CKD: report of an expert panel convened by the Centers for Disease Control and Prevention. Am J Kidney Dis 2009;53:522-535.

40 James MT, Hemmelgarn BR, Tonelli M: Early recognition and prevention of CKD. Lancet 2010;379:1296-1309.

41 Perico N, Bravo RF, De Leon FR, Remuzzi G: Screening for chronic kidney disease in emerging countries: feasibility and hurdles. Nephrol Dial Transplant 2009;24:13551358 . 